\title{
An Intellectual Genealogy Graph Affording a Fine Prospect of Organizational Learning
}

\author{
Mitsuru Ikeda ${ }^{1}$ and Yusuke Hayashi ${ }^{1}$ and Hiroyuki Tsumoto $^{1}$ and Riichiro Mizoguchi ${ }^{1}$
}

\begin{abstract}
The word of "learning", in a wide sense, is used as a part of the social system of education and it has been attracting researchers' interest in our research area of educational systems. The goal of this research is to support creation and inheritance of organizational intellect, that is, "learning" in an organization. In this paper, we will propose an "Intellectual Genealogy Graph," which is a model representing chronological correlation among persons, activities, and intellect in an organization. The intellectual genealogy graph is a basis of intelligent functions which is useful for surveying current learning conditions and clarifying the intellectual role of individuals, organizations, and documents in the organization.
\end{abstract}

\section{INTORODUCTION}

We continue to learn during our lifetimes. As researchers, for example, we learn basic knowledge through 'book learning', acquire up-to-date knowledge from the literature, develop original knowledge for ourselves, and then disseminate it to society. In this sense, we can share the idea that "life is a continuous process of learning." Usage of the word "learning" here has a rather wide sense; it is subtly different from the customary sense in which we use it to refer to the learning process established as a part of the social system of education.

"Learning" in a wide sense includes various forms of learning: for example, workplace learning, life-long learning, organizational learning, and so on. Viewing learning as an implicit, daily, long-term, practical activity is an important trend in many research areas related to the area of computers in education. As examples, the concepts of social constructionism in psychology[1], organizational learning[2] or knowledge creating companies[3] in management, and knowledge management sy stems in information technology[4][5] have been closely related to our research areas. In our area of intelligent educational systems, needless to say, "learning" in a wide sense has been attracting researchers' interest. Fisher's series of works on life-long learning[6] and integration of collaborative learning and knowledge management[7][8][9] are typical approaches in the same vein.

Along a similar line of thought, this research aims to develop a model of learning in a wide sense. Needless to say, we are all vaguely conscious of a similar model in our own minds which we apply to increase awareness of social relations among organization members; however, that model is implicit and not systemic in most cases. We propose a model called a "dual loop model", which

\footnotetext{
1 The Institute of Scientific and Industrial Research, Osaka University, 8-1, Mihogaoka, Ibaraki, Osaka, 5670047, Japan
}

shows how intellect is formed in individual life in organizations and works as a fundamental component of a learning support platform. The dual loop model indicates an ideal relation between individual activity and organizational activity and clarifies roles of individuals, activities, and documents as a vehicle for intellectual communication in organizational learning.

In this research project, we have been developing an IT platform, Kfarm[10][11], to develop users' pro-found social intellectual awareness in organization. Kfarm is a Web-browser-like workplace for users to carry out knowledge-oriented group activities, that is, searching, creating, organizing, and communicating information. All activities on Kfarm are recorded in organizational memory in the form of an "intellectual genealogy graph." This intellectual genealogy graph represents a trace of intellectual activities based on a dual loop model and shows how knowledge and the intellect are evolved in organization.

\section{A MODEL OF ORGANIZATIONAL LEARNING}

The terms 'knowledge,' 'intellect,' and so on are used with various meanings, so there appear to be no definite meanings for them[12]. Though it is difficult to define them strictly in a consistent manner, to show subjects of this study, we will take some exemplary definitions from the literature.

Brown and Duguid[13] argue convincingly that knowledge is more than just information because it

? usually entails a 'knower',

? appears harder to detach than information, and

? is something what we digest rather than merely hold.

Tobin draws distinctions between data, information, knowledge, and wisdom[14].

1. Data:

2. Information: $=$ Data + relevance + purpose

3. Knowledge: = Information+application

4. Wisdom: = Knowledge+intuition + experience

In this research, the term 'intellect' is used to express our idea similar to Brown and Duguid's argument about 'knowledge' and Tobin's 'wisdom'. Having an intellect means not only merely knowing something, but also digesting it through creation or practical use. It also means that the intellect cannot be separated from a person because it includes skill and competency. Therefore, we aim to support creation and inheritance of organizational intellect by managing information concerned with intellect. 


\subsection{Organizational learning}

It is considered that there are two viewpoints to clarify the goal of creation and inheritance of organizational intellect. One is a practical view and the other is an educational one. The practical goal is to produce a novel and significant intellect for an organization. The educational goal is to properly transmit significant intellect from past to future members of an organization and import significant intellect from outside of it. For both viewpoint, it is necessary to clarify what intellect each organization member has and what kind of shared workplace (Nonaka et al. call this "ba"[15]) makes it easy to transmit each intellect.

We attempt to attain such goals through our usual communication. Typical activities are, for example, acquiring, creating, and distributing intellect through the organization. Linking the activities are vehicles, e.g. conversations, books, or documents. By interpreting the activities and the vehicles, we can gain an awareness of others' intellect; those members usually do various activities to achieve creation and inheritance of organizational intellect based on that awareness. Such individual activities run the organization. However, it is difficult for members to do that because of the implicit nature of an ideal process of creation and inheritance of organizational intellect and content of vehicles actually used in activities. Consequently, to be properly aware of intellect and decide activity to attain the goal, it is necessary to clarify a model representing relations among an organization, individuals, intellect, vehicles, and activities from the view of creation and inheritance of organizational intellect.

Landes et al.[16] proposed a model of organizational learning in which knowledge is augmented with experiences of its application and developed a support tool based on it. The augmentation process is represented by the dependency among the documented experiences. In the best applicable domain of their idea, general knowledge is treated on an abstract level and the essential details of how to apply that knowledge in very specific situations are absent. Basing improvement initiative on experiences has a number of advantages, particularly in such a domain. On the other hand, intellectual roles of a person and intellectual communication in an organization are relatively less focused in this model.

Nonaka and Takeuchi proposed the SECI model, representing a knowledge conversion process and "Middle up-down management", which is a form of an organization to activate process[3][15]. In Middle up-down management, a "Knowledge practitioner (K-practitioner)" plays the role of generating creative power previously mentioned, while a "Knowledge producer (K-producer)" plays the role of coordinating between the top's visions and the K-practitioners' practical activities. Typical activities of the K-producer are given below:

? Proper understanding of organizational conditions.

? Assimilating new intellect with the organizational intellect.

? Distributing organizational intellect based on their vision/strategy.

These activities give direction to K-practitioners' activities.

Several studies have been made on information systems to support creation and inheritance of organizational intellect. Klamma and Schlaphof[17] stated the importance of interrelation between the processes of knowledge creation and usage and normal business processes both on a conceptual and a systemic level; they proposed a model-based approach for solving that Watanabe and Kojiri[8][18] arranged various kinds of educational support systems: CAI, CAL, ITS, and CSCL according to the

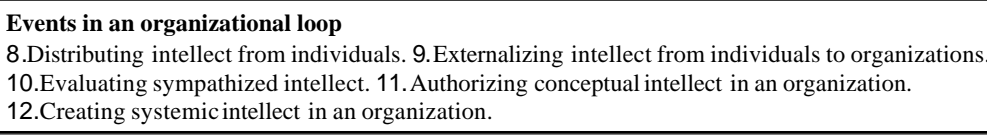

(A) A personal loop

(B) An organizational loop

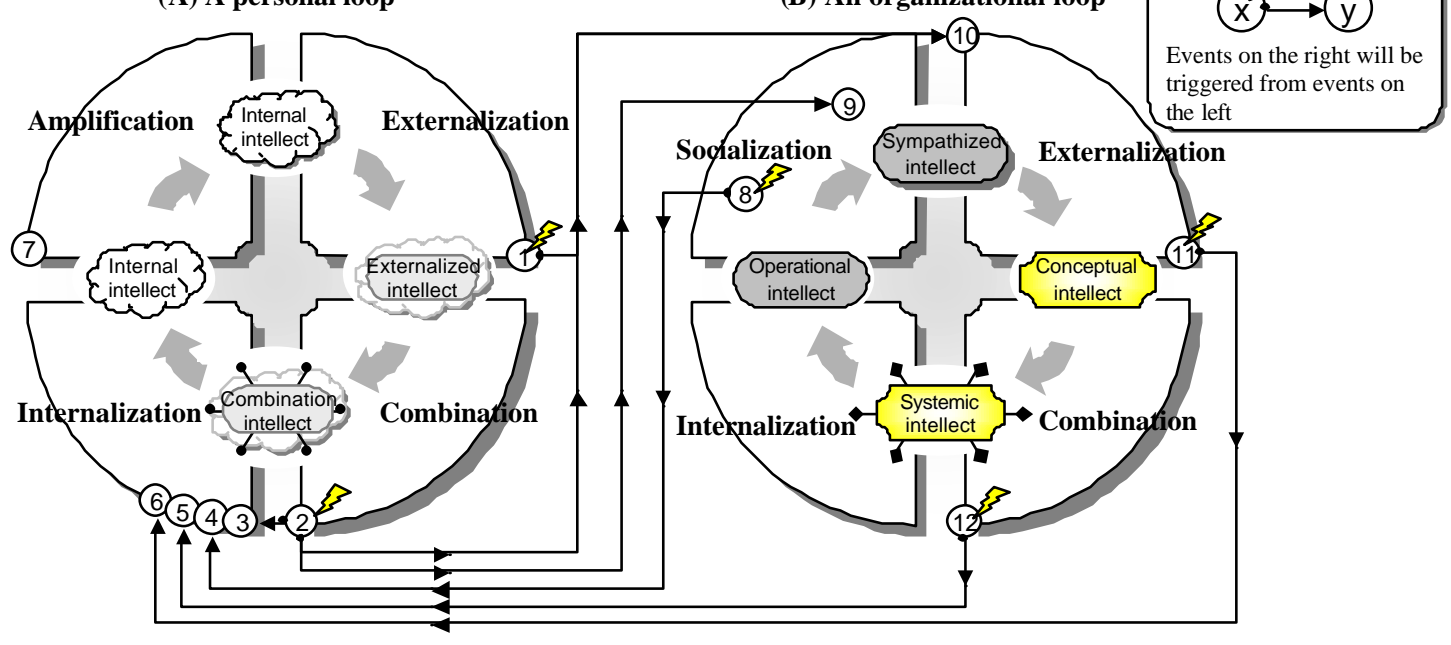

Events in a personal loop

1. Externalization of one's own intellect. 2. Combination of one's own intellect. 3. Self reflection. 4. Acquisition of intellect fromothers. 5. Learning organizational intellect.6. Acquiring course of organizational intellect(including 5.) 7. Amplifying one's own intellect.

Figure 1. Dual loop model (partly simplified) 
SECI model and proposed a learning environment architecture in which learners are able to change their learning style freely. The former study addressed the practical viewpoint and the latter study addressed the educational viewpoint, but each study ignored the other viewpoint.

In the viewpoint of awareness of intellect, Ogata et al. defined awareness of one's own or another's knowledge as "Knowledge awareness" and developed Sherlock II which supports group formation for collaborative learning based on learners' initiatives with the knowledge awareness[19]. This study supports group formation by learners' own initiatives, but lacks the organizational perspective.

The purpose of this study is building an organizational learning environment from several perspectives: practical and educational; and organizational and individual.

\subsection{Modeling an organizational intellect}

We produced a model supporting creation and inheritance of organizational intellect from two separate models: a process model and a content model. The process model is a model representing creation and inheritance processes of intellect. The content model is a model of the domain of intellectual activities.

Process model. We modeled an ideal abstract process of creation and inheritance of organizational intellect as a "dual loop model". Figure 1 shows the most abstract level of the model, which describes constraint on the relation between activities and change of the property of intellect. For example, socialization prescribes that resultant intellect draws a certain amount of symp athy in the organization; then, externalization of the intellect should follow. These activities are structured as a multi-tiered abstraction hierarchy in which the bottom layer consists of observable activities, for example, reading a document or distributing one. The hierarchy does not prescribe content of intellect concerned with activity, but the property of intellect. The dual loop model explains these activities from both viewpoints of the 'individual' as the substantial actor in an organization (a personal loop: Figure $1(\mathrm{~A})$ ) and the 'organization' as the aggregation of individuals (an organizational loop: Figure 1(B)). This model as a whole represents an ideal interrelationship among an organization, its members, and vehicles of intellect for the goal of creation and inheritance of organizational intellect. Further details of the dual loop model are shown in [10].

Content model. Most document management systems manage a document with indexes. However, it is difficult to share it in the organization since the meaning of the indexes is implicit and does not ensure consistency. Even if the document is shared, that will often be done on an implicit premise. In order to share and inherit intellect properly in an organization, it is necessary to form a basis to clarify the meaning of intellect. Semantic web[20] is an attempt to build a global consensus to share resources on the WWW.

Ontology[21] has been brought to public attention as a foundation. Ontology is a set of definitions of concepts and relationships to be modeled. Concepts related to tasks and domains of an organization are defined as the ontology to describe document content. The description is called the "conceptual index". Thus, intellect content in an organization is modeled with an index described on the basis of an ontology.

\section{INTELLECTUAL GENEALOGY GRAPH}

We compose a model of an organizational intellect as a combination of process and content, that is to say, the dual loop model and the ontology. The model is called an "intellectual genealogy graph". It represents chronological correlation among persons, activities, and intellect in an organization as an interpretation of activities of organization members based on these two models. Modeling an intellectual genealogy graph affords a good foundation for building intelligent support functions for the organizational activities given below.

? Clarifying a role for each member from a trail of his/her intellectual activities in organization. We call the role an "intellectual role", which characterizes a contribution of a person to the construction process of organizational intellect.

? Choosing a correct way to fill a gap between the current condition of organizational intellect and a desired one.

\subsection{Components of an intellectual genealogy graph}

Principal concepts appearing in an intellectual genealogy graph are as follows:

? Person is a career of intellect and a creator of it.

? Intellect is knowledge, skill, competency, and so on turned to practical use by a person. Categories of intellect are shown in Table 1.

? Vehicle is a representation of intellect and mediates intellect among people. As mentioned before, we assume that intellect can only exist in a person's mind and a vehicle of the intellect is not necessarily a complete representation of the intellect.

Table 1. Types of intellect

\begin{tabular}{|l|l|}
\hline Intellect type & Explanation \\
\hline Personal intellect & An intellect, which a person has personally. \\
\hline \begin{tabular}{|l|} 
Organizational intellect \\
Sympathized intellect
\end{tabular} & Types of intellect classified in view of relation to other's one and organizational one \\
\hline Conceptual intellect & An intellect consented or sympathized by others \\
\hline Systemic intellect & A conceptual intellect combined with other conceptual ones. \\
\hline
\end{tabular}


Table 2. Types of activities (partial)

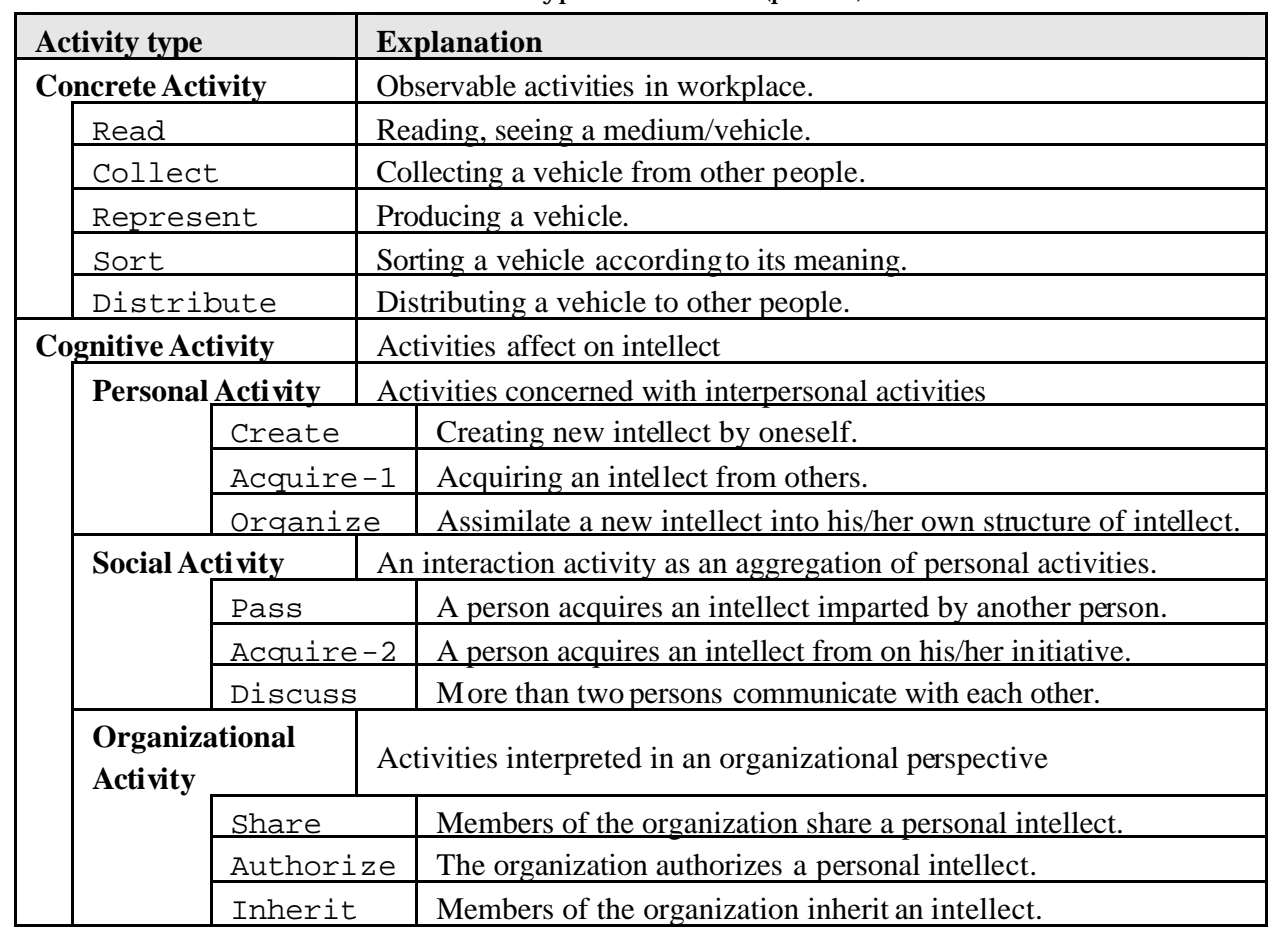

Table 3. Types of relations between intellects(partial)

\begin{tabular}{|l|l|}
\hline Relation type & Explanation \\
\hline created $(? a)$ & $\begin{array}{l}\text { A person originally creates an intellect } ? a \text { with no reference to other intellects in the } \\
\text { organization. }\end{array}$ \\
\hline imported $(? a)$ & A person acquires an intellect ?a from the outside. \\
\hline derived $(? a, ? b)$ & A person acquires an intellect ?a from another person's intellect $? b$ in the same meaning. \\
\hline inspired $(? a, ? b)$ & $\begin{array}{l}\text { A kind of modified relation, which represents the authorized significance of the } \\
\text { conceptual leap from } ? a \text { to } ? b .\end{array}$ \\
\hline authorized $(? a, ? b)$ & $\begin{array}{l}\text { A significance of an intellect } ? b \text { is authorized as an organizational intellect } ? a \text { by the } \\
\text { organization }\end{array}$ \\
\hline
\end{tabular}

? Activity is activity related to the intellect or a vehicle. Categories of activities are shown partly in Table 2.

An intellectual genealogy graph is built by abstracting a causal structure of cognitive activities from concrete activities based on the dual loop model. The structure clarifies mutual relation among personal activities, social activities, and organizational activities.

\subsection{Modeling an intellectual genealogy graph}

An intellectual genealogy graph consists of a vehicle layer and an intellect layer. The vehicle layer comprises persons, vehicles, and concrete activities. On the other hand, the intellect layer is an interpretation of the vehicle layer and consists of persons, intellects, cognitive activities, and relations among intellects. These relations are classified into some types by characteristics of changes of intellect as shown in Table 3. In the intellect layer, these relations are built from activities.

Hard data for modeling an intellectual genealogy graph is a time-series of concrete activities observed in the workplace. Firstly, a vehicle layer of the graph is built from the data. Then, a series of cognitive activities are abstracted from the vehicle layer based on the dual loop model and an intellect layer of the graph is constructed. Figure 2 shows an example of interpretation from concrete activities into cognitive activity and relationships between intellects derived by the translation. In this way, the intellectual genealogy graph records the formation of an organizational memory from activities.

\section{Kfarm: AFFORDING FINE PROSPECT OF INTELLECTUAL ACTIVITIES}

Kfarm is a system that we have been developing which embodies our conceptualization thus far. Kfarm is a distributed system consisting of a K-granary, at least one K-ranch house and some K-fields. The K-field and the K-ranch house are environments for a K-practitioner and a K-producer respectively. Those two play dual roles of sensors which watch a user's activities in a knowledge-oriented task and a display which shows information 


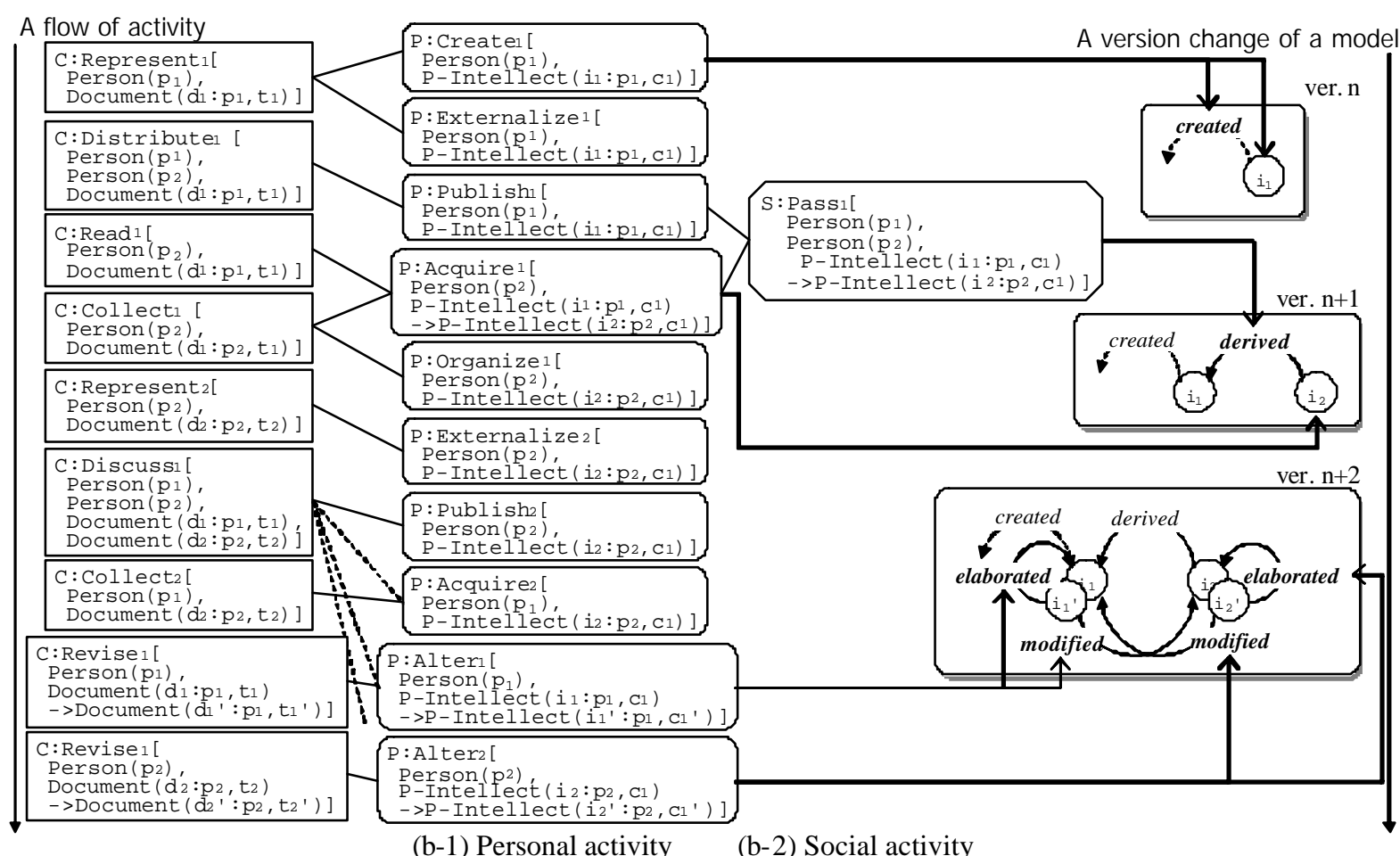
(a) Concrete activity
(b) Cognitive activity
(c) A model of intellect

Figure 2. An example of an intellect genealogy graph

about the organizational intellect according to their roles. The K-granary is a server. It interprets K-producers' and $\mathrm{K}$-practitioners' activities observed in the K-field and the K-ranch house and then aggregates and stores them as an organizational intellect.

\subsection{K-field}

A K-field provides K-practitioners with information needed for their knowledge-intensive tasks. Typical K-field functions are given below. These are designed based on activities defined in the personal loop in the dual loop model.

Sorting documents by folders: A K-field provides a bookmark window as a tool to store documents in folders with indexes. The indexes are converted to conceptual indexes in the K-granary.

Communication with others: In a $\mathrm{KW}$-window, a K-field indicates information about others and documents related to the document selected in the bookmark window. This information is based on intellectual roles of members and the document assigned on the intellectual genealogy graph.

\subsection{K-ranch house}

A K-ranch house supports K-producers' activities, e.g., recognizing the organizational condition and coordinating communication, cooperative work, and collaborative learning between K-practitioners based on the organizational vision/strategy.

Figure 4 shows windows of the K-ranch house which is under development. A launcher window shown in Figure 4(A) informs $\mathrm{K}$-producers about activities of K-practitioners in Kfarm. Figure 4(B) and (C) are monitor windows to provide a K-producer with detailed information of an organizational memory. In this case, an icon shown in Figure 4(A-1) indicates growth of an intellect supposed to be a sympathized intellect. If the K-producer clicks this icon, its details will be shown in the monitor window as shown in Figure 4(B) and (C). Figure 4(B) graphically indicates who sy mpathizes with the intellect through which document. Each node in Figure 4(C) indicates an intellect. Links between them indicate relations between intellects previously mentioned in Table 3.

Now, we will take a close look at the visualized intellectual genealogy graph. Figure 4(C) indicates a history of a generation of intellect in which the intellect $(\mathrm{C}-1)$ is the center of attraction. Broken arrows from intellect $(\mathrm{C}-2)$ to $(\mathrm{C}-1)$, for example, indicate an elaborated link. It is interpreted from the fact that ikeda makes a document referring to hayashi's document concerned with intellect $(\mathrm{C}-2)$ and puts the same term index and additional ones on the document. This information help the K-producer to clarify intellectual roles of members and documents concerned with the intellect. To illustrate a case of this, for example, it is supposed that hayashi is a person who has made a seed of a new intellect (C-2) and documents concerned with intellects (C-3) can be used as background information. 


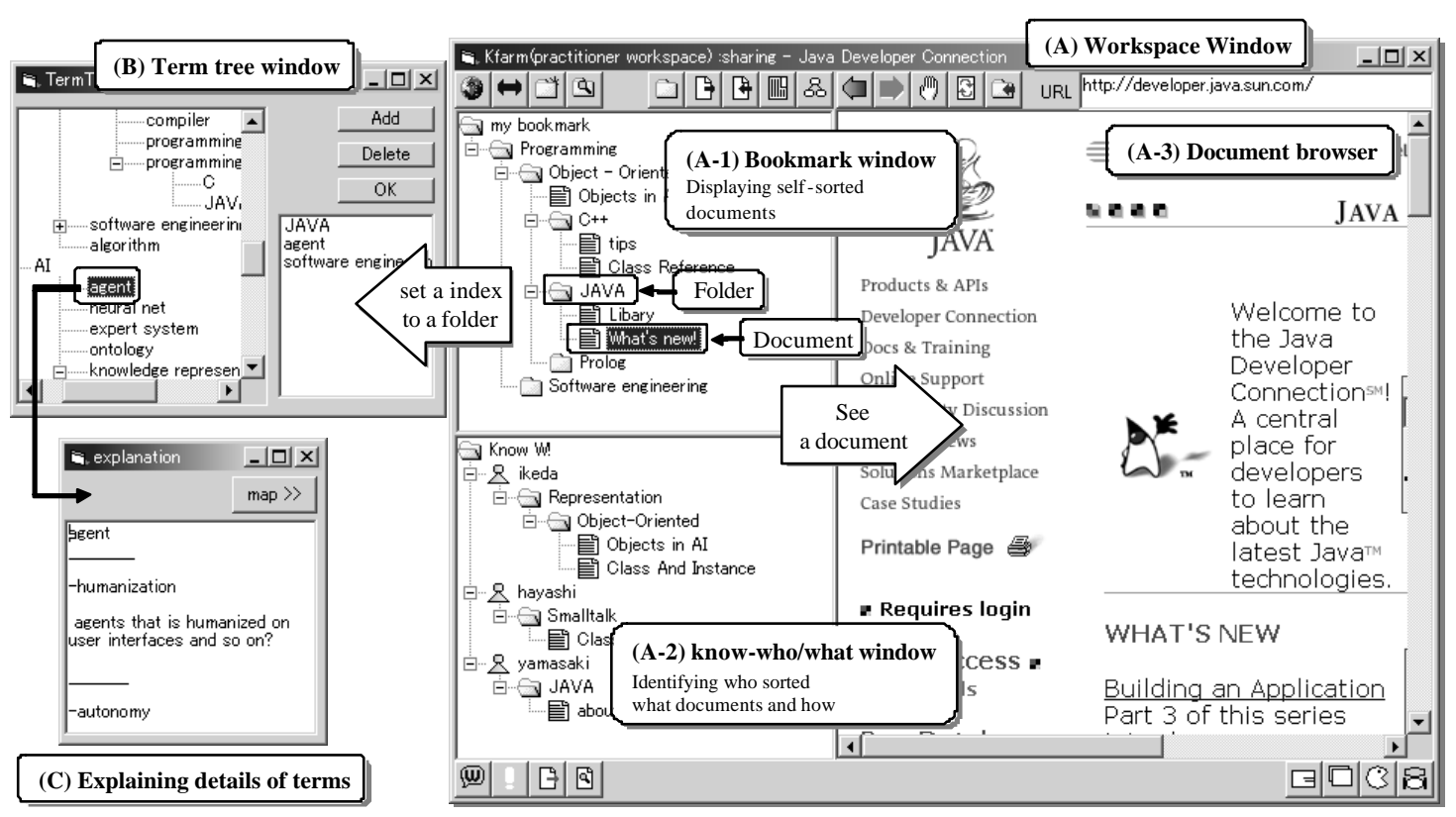

Figure 3. K-field

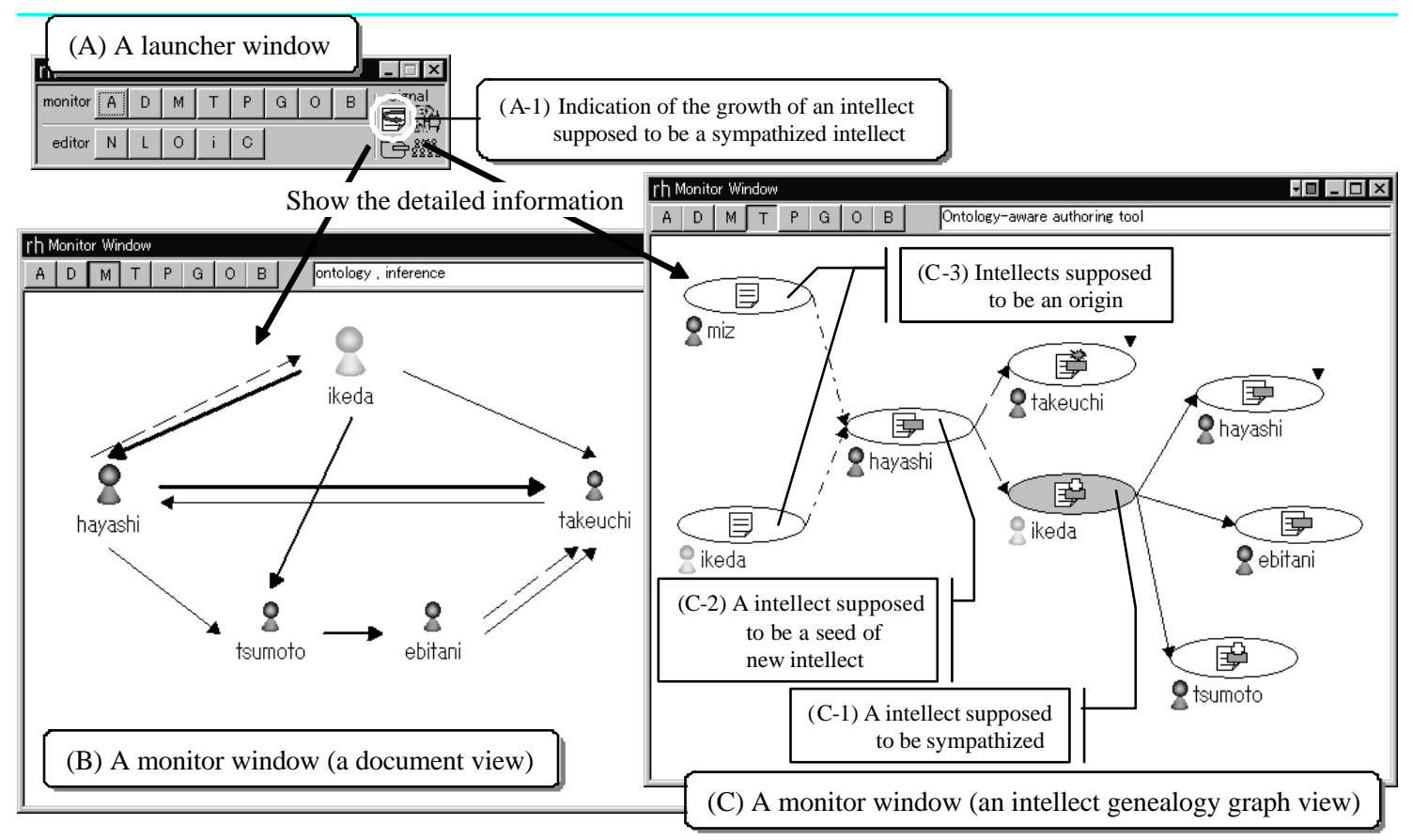

Figure 4. K-ranch house (under development)

\section{CONCLLUSION}

In order to support creation and inheritance of organizational intellect, that is, "learning" in a wide sense, it is important to abstract and interpret activities in the organization. In this paper, we have proposed the dual loop model and ontology as bases and introduced Kfarm as an embodiment of them. The intellectual genealogy graph is useful for individuals and organizations to survey current learning conditions and to clarify the intellectual role of individuals, organizations, and documents in the organization.

Future direction of this study will be to augment Kfarm in the following two ways.

? Support of arranging a collaborative learning space

? Model of the property of an organization

In the former, broadly speaking, it is considered that Kfarm itself is a space for less-regulated collaborative learning because it 
allows learner-directed communication. However, some processes of a dual loop model can be better achieved by rather regulated collaborative learning.

In the latter, generally, an organization has a hierarchical structure and a member belongs to some groups in the structure. Currently, we are introducing an organizational structure and developing a more flexible model of creation/inheritance of organizational intellect by considering that structure.

\section{REFERENCES}

[1] Doise W. and Mugny G.: The social development of the intellect, Oxford: Pergamon Press, 1984.

[2] Senge P. M.: The Fifth Discipline: The Art and Practice of Learning Organization, Doubleday, 1990.

[3] Nonaka I. and Takeuchi H.: The Knowledge-Creating Company: How Japanese Companies Create the Dynamics of Innovation, Oxford University Press, 1995.

[4] Decker S. and Maurer F.: "Editorial: Organizational memory and knowledge management", Int. J. Human-Computer Studies, 51, pp. 511-516, 1999.

[5] Fensel D.: Ontologies: A Silver Bullet for Knowledge Management and Electronic Commerce, Springer-Verlag Telos, 2001.

[6] Fischer G.: "Lifelong Learning - More Than Training, Special Issue on Intelligent Sy stems/Tools in Training and Life-Long Learning". In Eds.: Mizoguchi R. and Piet A.M. Kommers, Journal of Interactive Learning Research, Vol. 11, No. 3/4, pp.265-294, 2000.

[7] Eleuterio M. A., Bortolozzi F., and Kaestner C.A.: "The Roles of Ontologies in Collaborative Virtual Learning Environments", Proc. of ECAI2000 Workshop on Analysis and Modeling of Collaborative Learning Interactions, pp.31-35, 2000.

[8] Watanabe, T.: "Knowledge Management architecture of Integrated Educational Support", Proc. of ICCE/SchoolNet 2001, pp.1138-1141, 2001.

[9] Ayala G.: "Intelligent Agents Supporting the Social Construction of Knowledge in a Lifelong Learning Environment", Proc. of NTCL2000, pp.79-88, 2000.

[10] Hayashi Y., Tsumoto H., Ikeda M., and Mizoguchi R.: "Toward an Ontology -aware Support for Learning-Oriented Knowledge Management", Proc. of ICCE/SchoolNet 2001, pp.1149-1152, 2001.

[11] Hayashi Y., Tsumoto H., Ikeda M., and Mizoguchi R.: "Kfarm: A Knowledge Management Support System Based on Dual Loop Model”, Proc. of PYIWIT'2002, pp.235-242, 2002.

[12] Liebowitz J. (Eds.): Knowledge Management Hand Book, CRC Press, 1999.

[13] Brown J. S. and Duguid P.: "The Social Life of Information", Harvard Business School Press, Boston, 2000.

[14] Tobin D.: Transformational Learning: Renewing Your Company thought Knowledge and Skills, John Wiley and Sons, 1996.

[15] Nonaka I., Toyama R., and Konno N.: "SECI, Ba, Leadership: a Unified Model of Dynamic Knowledge Creation”, Long Range Planning, 33, pp. 5-34, 2000.

[16] Landes D., Schneider K., and Houdek F.: "Organizational learning and experience documentation industrial software projects", Int. J. of Human-Computer Studies, 51, pp.643-661, 1999.

[17] Klamma R. and Schlaphof A.: "Rapid Knowledge Deployment in an Organizational-Memory-Based Workflow Environment", Proc. of ECIS 2000, pp. 364-371, 2000.

[18] Kojiri T., and Watanabe T.: "HARMONY: Web-based Adaptive Collaborative Learning Environment", Proc. of ICCE/SchoolNet 2001, pp.559-566, 2001.

[19] Ogata H., Matsuura K., and Yano Y.: "Active Knowledge Awareness Map: Visualizing Learners Activities in a web Based CSCL Environment", Proc. of NTCL2000, pp.89-97, 2000.

[20] W3C Semantic Web: http://www.w3.org/2001/sw/

[21] Mizoguchi R. and Bourdeau J.: Using Ontological Engineering to Overcome AI-ED Problems, Int. J. of Artificial Intelligence in Education, Vol.11, No.2, pp.107-121, 2000 
